\title{
Implicações das atuais políticas educacionais na formação de professores em Educação Física: um estudo sobre a subjetividade do professor
}

\author{
Implications of current educational policies in the \\ Physical Education teachers' training: a study on the \\ teacher's subjectivity
}

\section{Implicaciones de las políticas educativas actuales en la formación del profesorado en Educación Física: un estudio sobre la subjetividad del profesor}

\author{
Matheus Bernardo Silva* \\ Lígia Regina Klein ${ }^{* *}$ \\ Maria Auxiliadora Cavazotti**
}

\begin{abstract}
Resumo: Este artigo busca problematizar a ontologia que fundamenta os documentos oficiais atinentes à formação dos professores de Educação Física. O referencial teóricometodológico para essa problematização é o materialismo-dialético. A fundamentação dos documentos oficiais citados cinge-se à formação "por competências" associada à "prática reflexiva". De maneira explícita ou implícita, tal política de formação busca atender às orientações e às necessidades da acumulação flexível, por sua vez, fundada na reestruturação produtiva e em sua expressão política, o neoliberalismo. A formação teleologicamente orientada para tais relações de produção, embora pareça vanguardista, é nucleada por um conservadorismo que se evidencia no não enfrentamento das contradições sociais. Conclui-se que a subjetividade dos professores é limitada em proveito de uma formação adaptativa ao processo de alienação.
\end{abstract}

Palavras-chave: Políticas Educacionais. Formação de Professores. Educação Física.

\begin{abstract}
This paper seeks to problematize the ontology that underlies the official documents related to the physical education teachers' training. The theoretical and methodological framework for such questioning is dialectical materialism. The reasoning of the official documents cited is confined to training "Competence", linked to "reflective practice". Explicitly or implicitly, such training policy seeks to meet the guidelines and requirements of flexible accumulation, in turn, based on productive
\end{abstract}

\footnotetext{
*Doutorando do PPGE - UNICAMP. E-mail: <matheusbernardo25@gmail.com>

*** Professora da Universidade Federal do Paraná (UFPR). E-mail: <lr.klein@uol.com.br>

${ }^{* * *}$ Professora do Centro Universitário Internacional (UNINTER). E-mail: <maccavazotti@hotmail.com>
} 
restructuring, and its political expression, the neoliberalism. The teleologically oriented training towards such relations of production, although it seems avant-garde, is seeded by a conservatism that is evident in not facing social contradictions. The results revealed that the teachers' subjectivity is limited in favor of an adaptive training to the alienation process.

Keywords: Educational Policies. Teacher training. Physical Education.

Resumen: Este artículo trata de la ontología que subyace en los documentos oficiales relativos a la formación de los profesores de Educación Física. El marco teórico y metodológico para tal cuestionamiento es el materialismo-dialéctico. Se busca demostrar que los méritos de los documentos oficiales citados se limita a la formación "Competencia", vinculado a la "práctica reflexiva". Explícita o implícitamente, como la política de formación busca cumplir con los lineamientos y requerimientos del modo de producción capitalista, en su fase actual de desarrollo. La formación orientada teleológicamente esas relaciones de producción, aunque parece de vanguardia, se siembra por un conservadurismo que se manifiesta en no enfrentar las contradicciones sociales. Llegamos a la conclusión de que la subjetividad de los profesores se limita a favor de un proceso de formación de adaptación de la alienación.

Palabras-clave: Políticas educativas. Formación del profesorado. Educación Física.

Até o presente momento os homens fizeram falsas representações sobre si mesmos, sobre o que são ou deveriam ser. Organizaram suas relações em função de representações que faziam de Deus, do homem normal etc. Os produtos de sua cabeça acabaram por se impor à sua própria cabeça. Eles, os criadores, renderam-se às suas próprias criações. Libertemo-los, pois, das quimeras, das ideias, dos dogmas, dos seres imaginários, sob o jugo dos quais definham. Revoltemo-nos contra este predomínio dos pensamentos. Ensinemos os homens a substituir estas fantasias por pensamentos que correspondam à essência dos homens [...].

(MARX; ENGELS, 1996, p. 17)

\section{Considerações iniciais}

O presente trabalho parte do pressuposto de que o processo econômico contemporâneo caracteriza-se por um regime de acumulação flexível do capital (ABRAMIDES; CABRAL, 2003; HARVEY, 2012; KUENZER, 2007; NETTO, 1994). Nos estudos que realizamos - coletivamente no nosso grupo de estudo e especificamente nas interlocuções de orientação de dissertação de mestrado - foi possível identificar que, assim como ocorre em outras áreas de formação, 
também na Educação Física escolar observa-se o atrelamento aos atuais condicionantes sociais, vale dizer, essa formação sofre o impacto das especificidades do regime de acumulação flexível do capital.

Conforme Abramides e Cabral (2003), o processo de reestruturação do capital foi deflagrado na década de 70 do século passado, especialmente em decorrência da crise mundial do petróleo e da queda tendencial da taxa de lucro. Esse movimento do capitalismo apoiou-se em um duplo ajuste estrutural: o ajuste na esfera da produção, ou seja, a reestruturação produtiva, que conforma a base material da sociedade, e o ajuste na esfera política do Estado, que se convencionou denominar de "neoliberalismo".

O elemento articulador das duas esferas - a produtiva e a política - é a acumulação flexível, que, segundo Harvey (2012, p. 140),

[...] se apoia na flexibilidade dos processos de trabalho, dos mercados de trabalho, dos produtos e padrões de consumo. Caracteriza-se pelo surgimento de setores de produção inteiramente novos, novas maneiras de fornecimentos serviços financeiros, novos mercados e, sobretudo, taxas altamente intensificadas de inovação comercial, tecnológica e organizacional.

Portanto, de maneira mais geral, compreendemos a acumulação flexível do capital como um movimento que teve, como objetivo inicial, promover alterações no modo de produção de maneira a ultrapassar o modelo "rígido", caracterizado pela organização do trabalho, específica do taylorismo-fordismo, e instaurando a produção por meio da acumulação flexível.

$\mathrm{Na}$ busca de novos mercados, bem como da reorganização dos mercados existentes, a reestruturação produtiva também se vale da atenção às "especificidades e diversidades" culturais e regionais, reportando-se, conforme lecionam Netto e Braz (2011, p. 226), “[...] para as peculiaridades de 'nichos' particulares de consumo". Por outro lado, a crise estrutural obriga o capital a enfrentar sistematicamente a resistência dos trabalhadores. Uma das formas mais notórias desse enfrentamento é a dupla cooptação dos trabalhadores: para a empatia com o modo de produção e para o esforço extra visando ao acesso de sua família ao consumo. Evidentemente, essa cooptação é instrumentalizada pelo processo de alienação e pela propaganda ideológica: busca-se a todo o momento debilitar a consciência de classe dos trabalhadores, isto é, busca-se interferir contundentemente na subjetividade dos indivíduos em proveito do aumento da produção e diminuição do valor da força de trabalho. A propaganda utiliza-se do ideário de que esta forma social é a mais avançada, posto que fundada na liberdade e na igualdade legal, e o quinhão de felicidade de cada um dependerá exclusivamente do seu mérito. O proprietário dos meios de produção "concede" aos trabalhadores o "benefício" da oferta do emprego - que, aliás, foi transformado em direito 
constitucional -, e os que souberem aproveitar a oportunidade tão generosamente concedida certamente alcançarão sua realização pessoal. Ademais, predomina o "[...] discurso de que a empresa é a sua 'casa' e que eles [os trabalhadores] devem vincular o seu êxito pessoal ao êxito da empresa; não por acaso, os capitalistas já não se referem a eles como 'operários' ou 'empregados' - agora, são 'colaboradores', 'associados' etc.” (NETTO; BRAZ, 2011, p. 226).

Entretanto, o paroxismo das contradições entre capital e trabalho, sob a égide da acumulação flexível, faz com que, nesse momento do modo de produção capitalista, surja a necessidade de que se produza uma subjetividade não só alienada sob o ponto de vista da divisão técnica do trabalho, mas também capaz de absorver consensualmente, ou seja, sem resistência, as novas demandas de produção e de consumo. Daí a necessidade de preconizar um "novo tipo de homem", evidentemente atrelado ao velho modo de produção, devidamente remodelado sob a reestruturação produtiva. Em outros termos, há mudanças profundas que exigem "um novo tipo de homem", mas tais mudanças se fazem, ainda, nos marcos da velha ordem, ou seja, sem o revolucionamento das matrizes sociais. Essa necessidade de um novo remendo no velho pano impõe o discurso de uma "nova concepção de mundo" que imprima, na subjetividade do trabalhador, a justificativa "plausível" para a sua alienação e, assim, se possam suprir as necessidades demandadas pela ordem do capital.

Assim, todas as instituições sociais, de uma maneira ou de outra, "obrigamse" a adequar suas ações às determinações intrínsecas da acumulação flexível do capital. As adequações são estimuladas por novo nível de tensão nas relações de produção. Entre esses estímulos, citaremos três, a título de exemplo, observando que todos se encontram intimamente articulados: aumento significativo da pressão sob a força de trabalho, quer por meio do desenvolvimento de novas tecnologias voltadas à produtividade - que aumentam enormemente o ritmo do trabalho -, quer pelo aumento do dispêndio individual de força de trabalho com o mesmo maquinário para o alcance de metas estabelecidas e, neste último caso, o artifício da "recompensa" como complementação salarial, é um exemplo amiúde observado; altas taxas de desemprego; rebaixamento dos salários, pelo barateamento da força de trabalho. Nesse quadro, não causa estranheza um retrocesso nas possibilidades trabalhistas de reivindicação por melhores condições de trabalho. Conforme Harvey (2012), há um enfraquecimento e uma (des)legitimação do poder reivindicatório dos sujeitos e, também, dos próprios sindicatos.

Assim, como as demais instituições sociais também a educação é chamada a reestruturar-se, uma vez que nela reverberam as acomodações da base material. A teleologia fundamental dessa reestruturação pedagógica cinge-se a novas formas de disciplinamento: agora já não mais rígidas, como no modelo anterior, mas flexíveis e autocontroladas pelo próprio indivíduo ou pela "célula" a que ele 
pertence no organismo da produção. Nessa direção, esclarece Kuenzer (2007, p. 1159):

Estas novas formas de disciplinamento vão contemplar o desenvolvimento de subjetividades que atendam às exigências da produção e da vida social, mas também se submetam aos processos flexíveis caracterizados pela intensificação e pela precarização, a configurar o consumo cada vez mais predatório e desumano da força de trabalho.

Entretanto, o controle do disciplinamento geral vem, necessariamente, articulado à demanda de certos nichos de trabalhadores mais especializados, dos quais, com todo o desenvolvimento tecnológico, o capital não pode desfazer-se. Impõe-se, portanto, um rígido controle do sistema de ensino que, ao mesmo tempo, garanta certas ilhas de excelência técnico-científica, em meio ao vasto oceano de medíocre formação escolar. $\mathrm{Na}$ impossibilidade de defender claramente essa desigualdade no processo de formação, impõe-se um sistema que se justifica, previamente, pela provável ocupação do indivíduo: seu destino educacional, então, será traçado por um programa de oferta de "competências" diferenciadas, demandadas por diferentes inserções no mercado de trabalho. Justiça seja feita: a cada qual, segundo suas competências. Como a escola é "para todos" e cada vez mais universalizada, consolida-se mais ainda a falsa ideia de "iguais oportunidades" e "aproveitamentos diferentes". Este último, certamente, de inteira responsabilidade do indivíduo. A ideia de competência, portanto, precede o ingresso na escola, perpassa a vida escolar e se realiza na inserção do sujeito no mercado de trabalho. Aqui, acompanhamos a hipótese de Kuenzer (2007, p. 1154) de que o atual modo de produção aprofunda o distanciamento e as diferenças entre as classes sociais, ou seja, “[...] aprofunda a dualidade estrutural, como expressão cada vez mais contemporânea, da polarização das competências". Mas não só: a própria noção de "competência" é manejada contra o próprio Estado, reiteradamente acusado de gigantismo paquidérmico, de paralisia burocrática, etc. Confundindo-se a função social do Estado e a função lucrativa das empresas, estabelece-se que ao Estado falta competência. Eis porque, entre outras razões, criam-se/eliminam-se funções públicas, sob a lógica de que, e aqui voltamos a nos valer da teorização de Kuenzer (2007, p. 1154), é necessária uma “[...] concepção de 'público não-estatal', que supõe o repasse de parte das funções do Estado e, portanto, de recursos públicos para a sociedade civil, alegando sua maior competência para realizá-las”.

É o impacto desse panorama, já bastante consolidado no Brasil nas últimas décadas, sobre as políticas educacionais que regulamentam a formação de professores de Educação Física que pretendemos analisar na sequência.

Quanto à sua organização, este artigo estrutura-se em três blocos, a saber: (a) apontamentos sobre o panorama da política educacional sobre a formação de 
professores no período "pós" reforma educacional, mais precisamente a partir da década de 1990; (b) as implicações dessa reforma educacional nas diretrizes que sustentam a formação de professores de Educação Física, principalmente nas décadas de 1990 e 2000; (c) considerações críticas sobre os impactos que a "nova" formação de professores de Educação Física, preconizada pela reforma educacional, acarreta à subjetividade dos indivíduos inseridos nesse processo de formação.

\section{A respeito da política educacional sobre a formação de professores no Brasil na década de 1990: em questão a reforma educacional}

A década de 1990, no Brasil, foi marcada por uma intensa reforma das políticas que regem a formação de professores. Documentos oficiais como os Referenciais para as Formações de Professores (BRASIL, MEC, SEF, 1998), as Diretrizes Curriculares Nacionais para a Formação de Professores da Educação Básica (BRASIL, CNE, 2001, 2002) e também documentos internacionais e regionais, formulados por órgãos multilaterais, interferiram intensamente na reforma da organização da educação no Brasil.

Obviamente, essa reforma não ocorreu de forma aleatória. As modificações nas diretrizes oficiais da educação em nosso país foram motivadas pelas mudanças no sistema produtivo que estavam acontecendo em escala mundial. Em suma, trata-se de mudanças educacionais destinadas a atender às determinações da reestruturação produtiva no que tange à formação e qualificação da força de trabalho. Conforme Mazzeu (2011, p. 148), essas mutações ocorreram nesse período histórico por estarem "[...] apoiadas na tese da reintegração das atividades de trabalho e da necessidade de emprego de mão de obra qualificada [...]".

Em virtude das características da chamada acumulação flexível do capital, a elaboração da reforma educacional pautou-se principalmente no atendimento da demanda por formação de indivíduos capazes de enfrentarem altos níveis de competitividade. A subjetividade desses sujeitos deveria, ao mesmo tempo, apresentar um ímpeto competitivo, bem como uma força emocional capaz de mantê-los íntegros a despeito de forte pressão no ambiente laboral. O esteio da subjetividade esperada traduz-se na absorção de demandas identificadas como, entre outras, flexibilidade, autonomia, polivalência. Em última instância, as estratégias propostas em documentos oficiais, sob os auspícios do plano institucional e econômico-administrativo preconizado pelo Estado, consistem "[...] na adaptação dos indivíduos às exigências do sistema capitalista no que se refere ao modo de produção e ao novo modelo de sociabilidade imposto pelo capital" (MAZZEU, 2011, p. 149). A elaboração e implementação dessas reformas na educação brasileira contou com a decisiva interferência de órgãos internacionais de atuação global ou regional, a citar alguns exemplos: o Banco 
Mundial, a Organização das Nações Unidas para a Educação, a Ciência e a Cultura (UNESCO), o Fundo das Nações Unidas para a Infância (UNICEF), o Programa das Nações Unidas para o Desenvolvimento (PNUD), a Comissão Econômica para a América Latina e o Caribe (CEPAL), entre outros.

Moraes (2003, p. 8), a respeito da influência e da interferência que esses órgãos tiveram na educação brasileira, a exemplo do que ocorreu em vários outros países, afirma:

No caso da educação, a literatura especializada tem indicado o balizamento do processo em curso segundo as recomendações de organismos multilaterais [...] que são apropriadas e difundidas pela vaga legislativa à mercê de interesses particulares. Essas recomendações conciliam-se com o desidrato do Estado brasileiro [...] em reduzir gastos com as áreas sociais e em fomentar a passagem da responsabilidade pública para a esfera privada. Ademais, esses lineamentos harmonizam-se com o peculiar interesse de empresários pelo "trabalhador de novo perfil", dotado de maiores competências técnicas e atitudinais, mais adequadas à produção flexível.

Um argumento essencial desses órgãos internacionais - argumento claramente absorvido pelos documentos oficiais atinentes à política da educação nacional, conforme se depreende da sua leitura - fundamenta-se na ideia da centralidade da educação no incremento do processo econômico, em especial nos países "em desenvolvimento". Dessa maneira, a formação de professores torna-se um componente importante para que a estratégia de desenvolvimento econômico possa fluir, razão pela qual passa a ser enfaticamente proposta às instituições educacionais do país. As recomendações por parte desses órgãos se sustentavam também - e não por coincidência - na justificativa do esforço para "[...] suprir as defasagens existentes entre as exigências do sistema produtivo e as possibilidades de resposta do sistema educativo na preparação de recursos adequados ao mercado de trabalho e à cultura de empregabilidade" (MAZZEU, 2011, p. 149).

Os apelos à educação adequada ao mercado de trabalho encontravam ressonância nos interesses dos próprios trabalhadores que, desesperados por um emprego, acreditavam mesmo que o problema estava em sua "precária" formação. Ocorre que sob tais apelos escondia-se um interesse maior: a transformação da sociedade em consumidora de uma nova gama de produtos, só tornados possíveis com o desenvolvimento da cibernética. Produzir consumidores, ou seja, produzir sujeitos capazes de consumir novas tecnologias era a parte "não dita" do discurso da educação voltada ao mercado de trabalho.

Vale lembrar, conforme salienta Moraes (2003, p. 10-11), que: 
Na década de 1990 era unânime o diagnóstico acerca do elevado grau de competitividade em um mundo ávido por informações. Os destinos da educação articulavam-se direta e explicitamente às demandas de um mercado insaciável e da sociedade dita do "conhecimento". Tornou-se freqüente a sugestão a que os governos implementassem sistemas educacionais mais eficientes e operacionais.

Essa importância de que se reveste a educação para o desenvolvimento econômico das nações foi destacada no documento da CEPAL (1990) intitulado "Transformación productiva com equidad", com referência explícita sobre a necessidade da formação e adaptação dos recursos humanos em prol da reestruturação econômica dos países da América Latina e do Caribe. Para Moraes, (2003, p. 10-11), "Tratava-se, como se lê no documento Cepal/Unesco [...], de estabelecer objetivos (cidadania e competitividade), critérios inspiradores de políticas (eqüidade e eficiência) e diretrizes de reforma institucional (integração nacional e descentralização)".

Outro movimento que ocorreu nesse mesmo ano foi a Conferência Mundial de Educação para Todos realizada em Jomtien (Tailândia), que buscou apresentar elementos na "Declaração Mundial de Educação para Todos" (BRASIL, 1993) para o aumento das taxas de escolaridade e a erradicação do analfabetismo. No entanto, levou-se em consideração, nesse documento, uma importante questão: ao mesmo tempo em que se fazia grande esforço para o aumento da escolaridade, também se buscava equilibrar, no "peso na balança", os recursos financeiros e humanos. As boas intenções de desenvolvimento da educação encontravam, assim, os limites financeiros, em dupla direção: por um lado, assegurar o não aumento dos gastos; por outro, não aumentar excessivamente o número de sujeitos qualificados, no interior do "exército de reserva". Trata-se de uma contradição objetiva na ordem do capital: desenvolver em contingente suficiente os "recursos humanos" para o modo de produção, sem entretanto dispender, nesse desenvolvimento - ou seja, em formação - mais do que a fração de mais-valia estritamente necessária.

Segundo Mazzeu (2011), as reflexões e as discussões realizadas nessa Conferência foram o marco para o início das reformas de cunho políticoeducacional nos países ${ }^{1}$ que, na década de 1990, apresentaram os maiores índices de analfabetismo. Portanto, os elementos contidos na Declaração supracitada, juntamente com as recomendações do "[...] Fórum Consultivo Internacional para a 'Educação para Todos' (Education for All), que ao longo da década de 1990 realizou reuniões regionais e globais de natureza avaliativa sob coordenação da UNESCO [...]", tiveram como finalidade a consolidação do documento

\footnotetext{
${ }^{1}$ Os países, conforme Mazzeu (2011) são Bangladesh, Brasil, China, Egito, Indonésia, México, Nigéria e Paquistão.
} 
referente à educação básica para desenvolver as intituladas "[...] Necessidades Básicas de Aprendizagem (NEBA) que compreendem os instrumentos essenciaispara a aprendizagem: leitura, escrita, expressão oral, cálculo e solução de problemas; e os conteúdos básicos da aprendizagem: conhecimentos, habilidades, valores e atitudes" (MAZZEU, 2011, p. 150-151, itálicos no original).

Ulterior a esse documento, elaborou-se e atingiu expressiva popularidade o documento do Bando Mundial (1995) - "Prioridades y estrategias para la educación" - com o intuito de expor que a relação entre investimentos na Educação Básica e o crescimento econômico são os fios condutores para a intervenção no campo da educação. Traça-se nesse documento "[...] as diretrizes políticas para orientar as reformas educacionais nos países de baixa escolaridade, buscando na educação a sustentação para uma política de contenção da pobreza" (MAZZEU, 2011, p. 151). Novamente volta-se a finalidade para a adaptação passiva dos indivíduos, a fim de suprir as tendências do mundo do trabalho e, por consequência, suprir as necessidades econômicas.

Quanto à formação docente, Mazzeu (2011, p. 152) esclarece que o Banco Mundial fomenta "[...] investimentos na melhoria do conhecimento do professor, considerando que a capacitação em serviço oferece melhores resultados para o desempenho escolar em comparação com a formação inicial, além de maiores vantagens com relação ao financiamento". Nesse documento, o Banco Mundial (1995) indica que a formação de professores deve ocorrer em um período mais reduzido, no nível superior, restringindo-se, no que tange aos conteúdos, apenas aos aspectos pedagógicos. Desse modo, o enfoque era a diminuição do tempo de formação desses profissionais, inclusive priorizando, para os docentes, a capacitação em serviço. Essa capacitação em serviço atenderia à ótica do Banco Mundial (1995), na medida em que reduziria os custos de formação, adequandose, inclusive, à formação docente a distância, tanto para a "reciclagem" - termo recorrente à época - de professores já formados, como para a própria formação inicial de professores.

O relatório entregue para a UNESCO, formulado pela Comissão Internacional sobre a Educação para o Século XXI, também foi um documento de referência para a reforma educacional da educação no Brasil. Essa Comissão tratou de apresentar uma nova contextualização e intervenção para a educação, com o intuito de propor mais elementos para a formação do indivíduo na intenção de adaptação a contínuas mudanças do mundo do trabalho. Mazzeu (2011, p. 153, itálicos no original) indica trata-se "[...] do conceito de educação como um continuum: o aprender a aprender, edificado sobre quatro pilares que sintetizam o caráter de prontidão que deve ser formado nos educandos. São eles: aprender a conbecer, aprender a fazer, aprender a viver juntos e aprender a ser". No que se refere à formação de professores, esse relatório reafirma as propostas levantadas 
pelo Banco Mundial (1995) e, nesse sentido, propõe uma formação por meio de "[...] competências e para a pesquisa (com vistas à resolução de problemas) como eixo articulador dos processos formativos, tendo como norte a reflexão sobre a prática" (MAZZEU, 2011, p. 154).

Eis o contexto dessas fundamentações que orquestram o sistema educacional para um novo direcionamento, na busca de atender as necessidades e as demandas da reestruturação econômica. No Brasil, a "associação" da política educacional da década de 1990 com as novas formulações da educação em escala mundial teve início, ainda segundo Mazzeu (2011, p. 155),

[...] na Era Collor, ganhando força nos Governos Fernando Henrique Cardoso (1995-2002) com o lema 'modernização' e da 'globalização'. Nesse contexto, a educação apresentava-se como elemento principal para a erradicação da pobreza e para a retomada do crescimento e do desenvolvimento econômico do país.

A adequação das diretrizes dos organismos internacionais à realidade brasileira foi expressa, inicialmente, no "Plano Decenal de Educação para Todos" (com vigência de 1993 a 2003), elaborado sob o governo de Itamar Franco. Nesse documento foram expostas as estratégias e metas para o Brasil, com base no documento formulado em Jomtien. Além disso, a formulação do documento configurava uma sinalização de que o Brasil assumia e se dispunha a implementar as orientações dos órgãos multilaterais criando uma nova política de educação no país, na qual se incluía, como dimensão basilar, a própria formação dos professores.

Obviamente, os documentos que vieram após esse Plano Decenal buscaram apresentar elementos para a educação baseando-se, também, nas diretrizes elencadas pelos órgãos multilaterais. É o que ocorre, por exemplo, no governo Fernando Henrique Cardoso - que se seguiu ao governo de Itamar Franco e que deu continuidade, aprofundando-a, à política educacional anterior. No governo de Fernando Henrique Cardoso, além das estratégias adotadas na época dos documentos, diretrizes e referenciais elaborados, contribuíram para institucionalizar "[...] mecanismos competitivos e meritocráticos como orientadores de investimentos nas instituições escolares [...]"; também "[...] procurou-se intervir na lógica da organiz̧ação escolar e das práticas educativas, propondo mudanças no sistema de formação docente" (MAZZEU, 2011, p. 156, itálicos no original).

No entanto, a grande mudança na formação de professores no Brasil, a partir da década de 1990, estabeleceu-se na elaboração e institucionalização da “Lei de Diretrizes e Bases da Educação Nacional" (LDB) n. 9.394/1996 (BRASIL, 1996), que tratou, de forma articulada os vários elementos constituintes da educação, entre eles a formação de professores desde a Educação Básica até o 
Ensino Superior. Na lógica das novas diretrizes, o documento deu ênfase aos Institutos Superiores de Educação (IES), iniciativa que "[...] buscou atender à orientação das agências multilaterais por uma formação inicial mais rápida e flexível, abstraindo do processo de formação do professor a pesquisa e a extensão e atribuindo forte ênfase à formação pela prática” (MAZZEU, 2011, p. 156).

Por outro lado, conforme lúcida interpretação de Saviani (2011), a formação do professor era orientada, na LDB (BRASIL, 1996), para uma forte tendência à especialização:

[...] o vetor da política educacional para o nível superior no Brasil, desde o Governo Fernando Henrique Cardoso (FHC), tem sido a chamada diversificação de modelos. Daí o surgimento de diferentes tipos de institucionalização oferecendo as mais variadas modalidades de cursos. Daí, também, a descaracterização das próprias universidades com a admissão, chancelada pela nova LDB, da organização de universidades especializadas por campo de saber. (SAVIANI, 2011, p. 440).

No bojo ainda das determinações da LDB (BRASIL, 1996), foram estabelecidas normativas para a formação de professores, a citar: os Referenciais para a Formação de Professores - RFP - (BRASIL, MEC, SEF, 1998) e as Diretrizes Curriculares Nacionais para a Formação de Professores da Educação Básica (BRASIL, 2001).

Os RFP afirmaram sua legitimação dos RFP (BRASIL, MEC, SEF, 1998) alegando, conforme Mazzeu (2011, p. 157), “[...] um suposto consenso acerca dos pressupostos sobre os quais deve ser guiada a formação do professor da educação infantil e séries iniciais do ensino fundamental". Esse documento, a despeito de admitir a necessidade de maiores investimentos na educação para garantia da valorização docente e para a melhoria da infraestrutura do ambiente educacional, também prioriza as tendências que pretendem "modular" a formação docente em proveito de um "novo perfil" de professor, adequado às exigências da reestruturação produtiva, explicitados nos documentos das agências internacionais. Em síntese, o documento alinha-se às tendências para a formação desse "novo professor", dotado de "novas competências" e capaz de refletir sobre a sua própria prática, apoiando-se, também, nas premissas expostas no "Relatório Jacques Delors"3, para legitimação da ênfase na importância da Educação Básica.

\footnotetext{
${ }^{2}$ A autora elucida que esse "consenso" nada mais foi do que um recurso da Secretaria de Educação Fundamental, que, na elaboração dos RFP (BRASIL, MEC, SEF, 1998), convocou uma equipe de indivíduos que possuíam ligação com a educação: as diversas equipes que atuam no Ministério da Educação, consultores, pareceristas, pesquisadores e autores do país. Trata-se, pois, de um "consenso" produzido por uma minoria de parceiros.

${ }^{3}$ Estamos nos referindo ao relatório que foi realizado para a UNESCO esmerado pela "Comissão Internacional sobre Educação para o Século XXI", que contou com a coordenação do economista francês Jacques Delors. "Tal relatório foi publicado no Brasil em 1998, com apresentação do então ministro da Educação, Paulo Renato Costa de Souza, em que ele realça a importância desse documento para o cumprimento da tarefa, à qual o MEC estava voltado, de repensar a educação brasileira” (SAVIANI, 2011, p. 433).
} 
Destarte, o documento RFP (BRASIL, MEC, SEF, 1998) enfatiza que a formação de professores "[...] seja orientada pela construção de competências profissionais com vistas à resolução de situações-problema e a um saber-fazer que privilegie as aprendizagens específicas e necessárias à atuação profissional para a incerteza e a imediaticidade do cotidiano escolar". Ademais, defende uma "formação reflexiva", em que a atividade pedagógica dar-se-ia por meio do "[...] conhecimento na ação, reflexão na ação e reflexão sobre a ação e considera que a prática reflexiva deve configurar-se como uma atitude cotidiana do professor em busca da compreensão da realidade educativa e da própria prática” (MAZZEU, 2011, p. 158, itálicos no original).

Saviani (2011) aponta para o caráter mais amplo do modelo de formação traçado nos documentos oficiais, o qual transcende os muros da escola e determina influências pedagógicas em esferas extraescolares, no país:

[...] delinearam-se das bases pedagógicas que vêm orientando tanto as reformas educativas acionadas em diferentes países e especificamente no Brasil, como as práticas educativas que vêm sendo desenvolvidas desde a década de 1990. Tais práticas se manifestam com características light, espraiando-se por diferentes espaços, desde as escolas propriamente ditas, passando por ambientes empresariais, organizações não governamentais, entidades religiosas e sindicais, academias e clubes esportivos, sem maiores exigências de precisão conceitual e rigor teórico [...]. (SAVIANI, 2011, p. 433-434, itálicos nosso).

Em suma, o alinhamento das políticas educacionais brasileiras à direção definida pelos organismos internacionais e regionais multilaterais determinou a direção e o ritmo das ações e intervenções na formação de professores em atenção às demandas da reestruturação produtiva posta em curso pelo modo de produção capitalista em escala mundial. Percebemos, então, que a reforma educacional em nosso país caminhou a passos largos para a adaptação da educação brasileira aos moldes estabelecidos pelos organismos multilaterais conservadores que, de uma forma ou de outra, "orquestraram" as diretrizes da educação para uma harmonização com a ordem do capital. A articulação entre a reestruturação produtiva e a política educacional é apreendida por Taffarel e Santos Jr. (2005, p. 121), que afirmam:

No bojo das estratégias para a recomposição do modo de produção capitalista, as ONGs, o terceiro setor, o voluntariado, encontraram terra fértil para sustentarem políticas compensatórias, focais, assistencialistas, que mantêm amplos setores das massas populares alienadas da raiz do problema da miséria, da fome, da ignorância e da violência.

É nos marcos dessa articulação que analisaremos, na sequência, as diretrizes e resoluções que direcionam a formação profissional de professores de Educação Física, no cenário nacional das duas últimas décadas. 


\section{Considerações sobre as diretrizes para a formação de professores de Educação Física nas décadas de 1990 e 2000}

Não é inédita a discussão sobre as determinações constituintes da formação de professores de Educação Física. Mais precisamente, desde quando foi criada a primeira escola civil de Educação Física, em 1939, no Brasil, diversos estudos foram realizados. Entretanto, intensificou-se essa discussão a partir da década de 1980, concomitantemente à decadência da ditadura militar. Durante o período ditatorial, a compreensão que se tinha de Educação Física e do Desporto pautava-se, predominantemente, por noções ainda vinculadas à ideia da saúde, do bem-estar e da recreação. Tal perspectiva, entretanto, esgotou suas possibilidades de responder às demandas postas pelo novo período histórico. Em decorrência, foi elaborada a Resolução n. 03/87 (BRASIL, 1987), que teve como principal objetivo encerrar o currículo mínimo e apresentar diretrizes para a composição e organização do currículo pleno, proporcionando dois formatos de titulação em Educação Física: o bacharelado e a licenciatura (TAFFAREL; LACKS, 2005).

Embora as alterações efetivas no currículo dos cursos de graduação em Educação Física das diversas universidades no Brasil viessem a ocorrer somente a partir do início da década de 1990, desde a publicação da Resolução n. 03/87 (BRASIL, 1987) já se iniciavam críticas ao seu conteúdo. Dessas insatisfações resultou a incorporação, no currículo do curso, de distintas disciplinas que tinham a função de problematizar a fundamentação e a intervenção dos cursos de licenciatura. Entretanto, essas intervenções pontuais levaram os cursos a uma descaracterização da licenciatura, acarretando uma formação com pouca coesão e pouco fundamentada para a atuação em distintos campos de trabalho, fora do ambiente escolar. Formularam-se, portanto, severas críticas direcionadas aos cursos de licenciatura, a exemplo do que também ocorria em relação aos cursos de bacharelado.

Foi em meio às discussões sobre as alterações do currículo da Educação Física que se estabeleceu, conforme Taffarel e Lacks (2005, p. 90), “[...] o ordenamento legal implementado pela política educacional do Ministério da Educação (Lei no 9.394/96, das diretrizes e bases para a educação, e o Edital n ${ }^{\circ}$ 04/97, das diretrizes curriculares para o curso superior)". Dessa forma, a Câmara do Ensino Superior - vinculada ao Conselho Nacional de Ensino (CNE) iniciou um processo de reformulação do currículo dos cursos de graduação de licenciatura, designando para essa função uma primeira comissão, constituída por um grupo de especialistas, com mandato por dois anos (BRASIL, 1998).

Essa reformulação, especificamente do currículo do curso de Educação Física, diferentemente da Resolução n. 03/87, propôs a formação superior em 
Educação Física em um curso de graduação que teria unicamente como título o de "graduado em Educação Física", extinguindo as titulações de bacharel e de licenciado e, de acordo com Taffarel e Lacks (2005, p. 91), "[... ] visando a atender às diferentes manifestações da 'cultura do movimento' da sociedade, considerando as características regionais, de mercado, relacionadas com o campo de atuação profissional". Assim o currículo foi estruturado de forma a contemplar: (a) conhecimento identificador da área, ou seja, a compreensão do curso como campo de formação específica; (b) conhecimento identificador do conteúdo específico, ou seja, "[...] o conjunto de competências específicas para o planejamento, execução, orientação e avaliação das ações do graduado em Educação Física [...]”; (c) carga horária total do curso de no mínimo 2.880 horas-aula - das quais, inicialmente, 300 horas-aula destinar-se-iam à prática de ensino, o que posteriormente passou a 400 horas-aula - prevendo-se, deste modo, a uma duração mínima de quatro anos e máxima de sete anos; (d) exigência de elaboração de trabalho de conclusão de curso. A comissão de especialistas ainda propôs a realização de atividades de pesquisa e extensão como práticas essenciais à formação de profissionais para a área.

Entretanto, no ano de 2000, extinguiu-se o prazo de dois anos de vigência da primeira comissão de especialistas, específica da área de Educação Física. Assim, no dia 08 de maio de 2001, foram aprovadas pelo CNE as "Diretrizes Curriculares Nacionais para a Formação de Professores da Educação Básica, em Nivel Superior, Curso de Licenciatura, de Graduação Plena” (BRASIL, 2001), que contemplavam também a licenciatura em Educação Física (TAFFAREL; LACKS, 2005).

Tais diretrizes configuraram um retrocesso, uma vez que foram desconsiderados os debates realizados na área e apresentados pela primeira comissão de especialistas da Educação Física. Essa denúncia é feita por Taffarel e Lacks (2005, p. 92), quando afirmam ter havido uma desconsideração dos documentos elaborados " $[\ldots]$ pelos movimentos dos educadores e encaminhados às comissões de especialistas de ensino de várias áreas do conhecimento da Secretaria de Ensino Superior, do MEC".

A concepção apresentada nas novas diretrizes determina a fragmentação do curso de Pedagogia, tal como nos demais cursos de licenciatura, em dois modelos distintos: licenciatura e bacharelado. Tais diretrizes acarretam, portanto, a perda de identidade dos profissionais da área, dando origem, por conseguinte, a

[...] agrupamentos cooperativistas e cria privilégios, fechando cada vez mais o mercado de trabalho. Isso leva à criação de códigos de ética como instrumentos de poder e de defesa de monopólios. Os códigos de ética são também usados como fator de coerção profissional, promovendo a censura prévia e impedindo a divulgação de novas ideias. (TAFFAREL; LACKS, 2005, p. 92). 
Lícito observar que essas diretrizes curriculares forjam-se como resposta às necessidades da adequação da educação ao mercado, tal como foram absorvidas elencadas na proposta de reforma educacional no Brasil. Instituiu-se, então, no processo da formação de professores o eixo nodal de uma nova meritocracia, agora fundada em novas competências e certificação ${ }^{4}$. Estão em pauta " [...] novos pressupostos para a formação de professores, fundados na promoção dos meios para o desenvolvimento do pensamento autônomo e no incentivo às estratégias de autoformação, nos quais grande ênfase é concedida ao desenvolvimento pessoal"'s (MARTINS, 2011, p. 9).

Ao mesmo tempo em que a nova política educacional era construída na esfera estatal, a resistência dos trabalhadores em educação ganhava corpo. Em meados de junho de 2001, em Curitiba, teve lugar um debate em que professores e alunos foram convidados a refletir e discutir sobre o Parecer 009/2001 com o objetivo de "[...] construir um outro documento com base nos entendimentos que as entidades representativas dos educadores já tinham acumulado" (TAFFAREL; LACKS, 2005, p. 93).

Contudo, essa resistência, que abarcava todas as áreas de formação, não se configurou suficientemente forte no campo da Educação Física. Com efeito, a segunda comissão de especialistas - ligada ao Conselho Federal de Educação Física (CONFEF) - reuniu a comunidade acadêmica para apresentar as diretrizes elaboradas pela primeira comissão de especialistas e instaurou uma discussão que tem como argumento a inobservância, pela primeira comissão, das diretrizes elencadas no Parecer 009/2001. O CONFEF também se posiciona reclamando que as proposições da primeira comissão não atendiam aos pressupostos oriundos do Parecer 009/2001. Com isso, homologou-se um novo parecer determinando que "[...] todas as áreas deveriam ter dois cursos específicos, um para a licenciatura e outro para o bacharelado" (TAFFAREL; LACKS, 2005, p. 94).

Em 2002, por ocasião do Fórum Nacional dos Cursos de Formação Profissional, bem como em outros fóruns regionais que atuaram em paralelo, o CONFEF defende a Resolução 046/02, documento que se tornou o principal embasamento para as diretrizes curriculares que foram homologadas pelo CNE por meio do Parecer n. 138/2002. Este parecer coadunou plenamente com as orientações já em voga e explicitadas pelo Parecer 009/2001 e, retroativamente, no que tange à formação de professores na área da Educação Física, retomou os laços com a Resolução em vigência na década de 1980, impondo à Educação

\footnotetext{
${ }^{4}$ Taffarel e Lacks (2005, p. 93) afirmam que "A certificação aparece na última versão das diretrizes, pois, em agosto de 2000, o Conselho Nacional de Educação discutiu a avaliação dos docentes. Uma avaliação que se dá a partir do desempenho dos alunos no "provão"'.

${ }^{5}$ A respeito dessa questão da formação de professores e os efeitos na atividade pedagógica, estaremos discutindo a seguir.
} 
Física as seguintes determinações: (a) o viés da aptidão física; (b) a desqualificação na formação dos professores, em virtude da fragmentação da formação entre bacharelado e licenciatura; (c) a alocação da Educação Física na área da saúde; (d) a orientação da formação de professores unicamente para a lógica do capital, agora sob o signo da reestruturação produtiva e sua expressão política, o neoliberalismo.

Essas (re) formulações no campo da formação de professores de maneira geral e, no caso específico, da formação de professores de Educação Física, expressam os movimentos sociometabólicos que são inerentes ao atual estágio da sociedade regida pelo modo de produção capitalista. Assim, nas últimas décadas, no Brasil, a educação - que não é um elemento abstrato e fora das determinações econômico-sociais - foi reestruturada por novas as políticas educacionais que expressam, entretanto, uma intervenção conservadora, atribuindo ao indivíduo a responsabilidade principal pelo seu sucesso ou seu fracasso na inserção no mercado do trabalho. Essas reformulações conformam-se a uma política de Estado, como afirmam Taffarel e Santos Jr. (2005, p. 122), em relação às “mutações” da formação de professores de Educação Física:

Após uma série de audiências públicas promovidas pelo CNE, acerca de diretrizes curriculares e duração de cursos, foram aprovadas, em março de 1004 - Resolução 07 de 31 de março de 2004, com base no Parecer no 058, de 18 de fevereiro de 2004 - as diretrizes paras os cursos de Educação Física. Nesse processo, destacamos a posição do MEC e seu representante no CNE - Éfrem Maranhão - que ressaltam a política de Estado expressa no Plano Nacional de Educação que indica as diretrizes na linha da ênfase nas competências, relacionadas, também, com o recém criado [na época] Ministério do Esporte e sua política para a área.

As determinações estabelecidas como políticas de Estado no direcionamento da Educação e, por conseguinte, da Educação Física, nas décadas de 1990 e 2000, foram realizadas no governo de Fernando Henrique Cardoso e tiveram continuidade no governo de Luís Inácio Lula da Silva. As propostas sobre as políticas educacionais já estabelecidas - a LDB e o PNE (Plano Nacional de Educação), por exemplo - triunfaram nos debates realizados por meio do Fórum Nacional em Defesa da Escola Pública.

Segundo Taffarel (2010, p. 32), no percurso das diretrizes que regem a formação em Educação Física, prevaleceram as seguintes problemáticas: “[...] a formação acrítica, a-histórica e a-científica; os currículos desportivizados [...]; ênfase no paradigma da aptidão física com forte influência da área biológica; apesar de usarem terminologias como saúde e qualidade de vida." Daí, ainda na análise da autora, que "Contraditoriamente, não se evidencia a proximidade da área com as revindicações colocadas nas licenciaturas em geral. A ênfase das 
preocupações curriculares recai na cientifização, ou seja, na busca do estatuto epistemológico da Educação Física e na formação via bacharelado".

Taffarel (2010, p. 32) apresenta uma interpretação crítica frente aos condicionantes da reforma educacional no Brasil muito semelhante aos posicionamentos e às reflexões dos intelectuais que utilizamos para nos fundamentarmos no primeiro momento desse artigo. Com efeito, a autora corrobora o posicionamento de que as orientações da reforma educacional, tanto para a educação em geral como para a Educação Física, “[...] estão permeadas pelas recomendações e orientações das políticas de cunho neoliberal, direcionando assim os vários campos do saber como a própria Educação Física".

Ainda, a respeito da reformulação educacional, diz Taffarel (2010, p. 33, itálicos nossos):

O que nos fica evidente considerando as proposições de reformulações curriculares da Educação Física da década de 1930 aos anos de 2000 é que ocorren um processo de desqualificação do professsor de Educaşão Física e essa desqualificação é mediada pela organização do trabalho pedagógico, com ênfase na dimensão do controle ideológico dos conteúdos e métodos. E isso é evidente nas propostas curriculares.

Essas considerações, ao mesmo tempo em que fecham o presente tópico, já abrem a questão que abordaremos na continuidade deste trabalho: por meio de um estudo bibliográfico, intentaremos apontar possíveis impactos que esse novo ordenamento das diretrizes curriculares para a formação de professores de Educação Física podem causar nos indivíduos que estão inseridos nesse processo de formação, ou seja, nesses professores em "formação".

\section{Impacto da formação profissional em Educação Física na subjetividade dos professores}

A compreensão que tivemos sobre as determinações econômico-sociais dos documentos oficiais que regem as atuais orientações para a formação de professores - tanto no âmbito geral como no campo específico da Educação Física - e com o auxílio de interlocutores que analisaram criticamente tais documentos, temos elementos para a problematização do impacto das reformas educacionais na subjetividade dos professores.

Em primeiro lugar, cabe destacar, da análise acima, que esses documentos oficiais promovem uma formação que descaracteriza a função educativa do professor, reduzindo o trabalho docente à mera reprodução de um exército de reserva em prontidão para as novas demandas do mercado de força de trabalho. Como "escapa" a essa formação uma teleologia mais ampla, a prática pedagógica pode ser reduzida a um mero saber-fazer circunstancial, calcado na imediaticidade 
dos fenômenos. Daí o fomento de uma pedagogia calcada em uma "prática reflexiva" e orientada para o desenvolvimento de competências. $\mathrm{Na}$ síntese de Teixeira (2013, p. 18), “[...] os saberes relativos ao desenvolvimento profissional docente devem ser aqueles construídos na e pela prática, colocando a formação por competências como substituta da formação teórica e acadêmica".

Cabe, pois, a seguinte problematização: quais os impactos incidentes na subjetividade dos indivíduos inseridos nesse processo de formação de professores de Educação Física, o qual se apoia em uma atividade pedagógica dita "prático-reflexiva", orientada para a formação de competências e legitimada por documentos oficiais que incentivam a formação de curta duração e a dissociação entre a licenciatura e o bacharelado, vale dizer, entre a teoria e a prática da função docente? Tal problematização atribui, ao nosso trabalho, a tarefa de argumentar sobre uma concepção de subjetividade articulada a determinada concepção de homem e de mundo.

Iniciamos explicitando uma ontologia materialista-histórica, cujo pressuposto fundamental é de que os homens fazem-se humanos na prática social criadora, ou seja, no trabalho. É social, em razão de que o trabalho pressupõe a cooperação; é criadora, porque essa cooperação é demandada pela criação de condições materiais de existência. Conforme Saviani (2004, p. 22) "[...] a questão da subjetividade se manifesta como indissociável da intersubjetividade". Ademais, cabe destacar, por outro lado, que o modo de produção capitalista eleva no nível global a socialização da produção. Articulando-se ambas as premissas, deduz-se, legitimamente, que todo processo que ocorre no seio do modo de produção capitalista interfere na formação da subjetividade dos indivíduos. Como Martins (2011, p. 126),

Partimos do pressuposto de que o homem é o sujeito da história, criador e reprodutor de suas condições de existência e, por conseqüência, autor de seu processo de personalização. O homem é um ser que produz pelo trabalho social os seus meios de subsistência e desta forma se produz a si mesmo.

A construção da subjetividade não pode ser explicada pelos dados que se situam nos elementos biológicos e muito menos por contingências. "Ainda que ambas possibilidades explicativas contenham algo de verdadeiro, não abarcam $o$ fenômeno em sua totalidade concreta, pois dicotomizam singularidade e sociabilidade, indivíduo e gênero humano" (MARTINS, 2011, p. 141, itálicos nosso). No caso da subjetividade dos indivíduos, a formação dessa categoria se configura por meio das relações sociais, ou seja, por meio da intersubjetividade que ocorre na intervinculação e interdependência entre a singularidade e a sociabilidade.

Concebemos, por conseguinte, que a atividade humana, ou seja, a "[...] atividade de produção dos meios de satisfação das necessidades humanas [...]" 
(DUARTE, 2013, p. 22), é a principal determinação para a formação da subjetividade. Contudo, o modo de produção capitalista, em decorrência da propriedade privada dos meios de produção e da relação de assalariamento, caracteriza-se pela dissociação entre o produtor e os meios de produção, isto é,, por uma condição de alienação do produtor em relação ao objeto de trabalho, aos instrumentos de trabalho, aos produtos do seu trabalho e, também, em relação aos demais sujeitos. Assim, a formação da subjetividade ocorre em meio a um processo de objetivo de alienação.

Segundo Gradella Jr. (2010, p. 134):

A alienação tem, portanto, origem objetiva, que decorre das relações de dominação estabelecidas pela divisão do trabalho no modo de produção capitalista. Nesse processo de alienação, as próprias relações de dominação acabam sendo vividas enquanto independentes das ações humanas, naturalizando-se; deixam, portanto, de ser concebidas pelos homens enquanto condições históricas e passíveis de superação. Dessa forma, o trabalho enquanto objetivação humana se descaracteriza, ou seja, o trabalho que possibilitou ao homem a superação dos seus limites biológicos e a construção de sua genericidade é, no capitalismo, fonte de alienação e desumanização [...].

Martins $(2011,144)$, a respeito da formação da subjetividade na organização capitalista, ou seja, levando em consideração a categoria da alienação, afirma que as relações dessa organização " [...] circunscrevem as condições da subjetividade dos indivíduos, e, sendo assim, o homem pertencente ao capitalismo é fundamentalmente o homem alienado, ainda que esta alienação se expresse em diferentes níveis e formas".

A mesma autora ainda adverte que a dissensão motivada pela alienação na envergadura da subjetividade

[...] acaba por opor a atividade psicológica a si mesma, pois os universos se significação social e pessoal que coabitam no indivíduo se tornam cada um deles o instrumento de negação do outro, comprometendo de forma decisiva a articulação entre as principais dimensões da atividade humana, isto é, entre suas dimensões objetiva e subjetiva. (MARTINS, 2011, p. 144-145).

Considerando que o "ser social" contemporâneo se estriba nas contradições entre capital e trabalho, não é descabido interpretar que as profundas e aceleradas mudanças no modo de produção capitalista afetam a subjetividade dos indivíduos. As relações econômicas que estão na matriz do ser social impõem suas regras e determinam dinâmicas às quais os sujeitos devem adaptar-se rapidamente, sob pena de exclusão social que pode, no limite, impedir até mesmo a mera sobrevivência. Ressalve-se, obviamente, a sempre presente possibilidade de revolucionamento radical dessa matriz, o que, entretanto, 
não logrou ocorrer. Como vimos no início deste artigo, o modo de produção capitalista enfrenta uma forte crise estrutural e busca controlá-la por meio de uma reestruturação produtiva cuja característica marcante é a flexibilização da produção. Quer isto dizer que a produção rege-se por um perfil extremamente flexível, impondo-se alterações rápidas e em larga escala, seja nos processos de trabalho, seja nos mercados de trabalho, seja nos produtos e padrões de consumo. Se são flexíveis todas essas esferas da produção, é evidente que à subjetividade que se encontra atrelada às intersubjetividades que, por sua vez, se reproduzem no processo produtivo da existência - se imponha um perfil igualmente flexível. Os sujeitos devem ser capazes de mudar rápida e profundamente, para adaptarse a um mundo extremamente mutante. Lembramos, aqui, a distinção qualitativa entre mudança e revolução: embora um acúmulo significativo de mudanças possa vir a exigir uma revolução, não significa que esta aconteça como resultado mecânico de dito acúmulo. O que observamos, no campo da educação em geral, e da Educação Física em especial, é um movimento de adaptação, mais do que de resistência. Se esta ocorre - e ocorre -, é em palcos exteriores às decisões estatais.

Com efeito, as premissas encontradas nos documentos oficiais que regem a formação de professores de Educação Física, conforme a acertada análise de Martins (2011, p. 126), “[...] escamoteiam a verdadeira essência humana, que é se realizar nas relações sociais, quando então as inúmeras possibilidades do ser humano se atualizam ou fracassam no processo histórico-social de sua autoconstrução".

A matriz social continua a realizar-se, extremando as suas contradições internas e carecendo, cada vez mais, impor-se como de interesse universal. Mas lhe é obstado revelar-se com franqueza. Daí a imposição de uma prática social devidamente edulcorada, de modo a tornar-se palatável pelo conjunto da sociedade. O escamoteamento, mencionado por Martins (2011), impõe, ao mesmo tempo que oculta, a matriz social. Ele é determinado pela própria impossibilidade política de autoexpressão dos interesses conservadores de dita matriz. Daí a necessidade política de apresentar os interesses conservadores, próprios de uma determinada classe, como interesses universais. A subjetividade é capturada inteiramente pela matriz social, mas interpretada apenas de maneira fragmentada e isoladamente da realidade social, ou seja, apenas subjetivamente.

No momento presente, na formatação da acumulação flexível do capital, as atuais políticas educacionais apresentam elementos que conservam e fomentam as bases do atual sistema de produção. Dessa forma, consideramos que tanto as políticas educacionais como os referenciais de cunho teórico-metodológico que interferem na atividade pedagógica dos professores, isto é, a abordagem por competências e a prática reflexiva, atuam de maneira a impor e ao mesmo 
tempo ocultar as determinações econômico-sociais. E o fazem com o recurso do aligeiramento da formação, seja pelo encurtamento cronológico do curso de formação, seja pelo empobrecimento dos conteúdos - com a substituição da ciência pela técnica ou, o que é pior, pela "opinião" acrítica. Nesse sentido, trata-se de uma formação adaptativa às demandas das práticas e relações laborais de caráter flexível. Nesse contexto, a própria subjetividade dos professores é "moldada" em proveito de uma adaptação do indivíduo perante as determinações da acumulação flexível do capital. Tais estratégias no âmbito pedagógico e no da formação em nada contribuem para o enfrentamento e para a superação da crise social que se profunda de modo incoercível, uma vez que, de acordo com Martins (2011 p. 145, itálicos no original),

Os motivos fundamentais da crise educacional contemporânea, do mal-estar docente, da síndrome de Burnout, do esvaziamento valorativo do trabalho docente são escamoteados. Denega-se que se subordinar, reproduzir, manter, se resignar etc. se revelam como mais uma das formas de trabalho alienado, restritivo ao verdadeiro desenvolvimento da consciência e da autonomia necessárias para toda e qualquer transformação. Outrossim, sabemos que a melhor maneira de se apresentar um fenômeno sem explicá-lo é recorrer à sua descrição fenomênica, realizando uma decodificação compreensiva pela qual se constata a incidência do fenômeno, sem julgá-lo e sem aprendê-lo para além de suas aparências.

As ações realizadas, nas décadas de 1990 e de 2000, no âmbito das políticas educacionais foram eminentemente vinculadas a um emaranhado de elementos e determinações que tiveram como objetivo produzir novas dinâmicas para o enfrentamento da crise do capital.

Tais dinâmicas expressam os interesses próprios da classe dos proprietários dos meios de produção e como tal impõem reformas na esfera educacional. Esses interesses, entretanto, se opõem aos interesses dos produtores diretos - os trabalhadores -, de tal modo que a formação requerida por aquelas dinâmicas subtrai conteúdos que interessam à classe trabalhadora. Saviani (2004, p. 49, itálicos nosso) assim define os interesses dos trabalhadores, no que se refere à formação de professores:

[...] os cursos de formação de professores devem visar à formação de seres humanos plenamente cultos, profundos conhecedores da história concreta dos homens, em lugar da formação de indivíduos "curtos", preconizada pela atual política de formação de professores que vem incentivando os cursos de curta duração dos institutos superiores de educação e suas escolas normais superiores.

$\mathrm{Na}$ especificidade das políticas educacionais e das diretrizes curriculares da formação de professores de Educação Física, as condições para a formação de professores não se alteram. Ocorre a mesma questão da fragmentação e da curta duração do curso que forma esses profissionais, com o consequente 
empobrecimento dos conteúdos e enfoque direcionado para uma acomodação adaptativa. Esse quadro recoloca a questão da resistência dos educadores, enquanto integrantes da classe trabalhadora. Concordamos, então, com o seguinte posicionamento de Taffarel (2010, p. 33):

O que nos fica evidente analisando as propostas curriculares e os dispositivos legais é que continuam atuais as proposições que não abandonam a análise das leis gerais do modo do capital produzir os bens materiais e imateriais, as leis que regem o estado burguês daí decorrente e suas relações de poder, as leis gerais da luta de classes decorrente da subsunção do trabalho ao capital que se expressa, não de maneira mecânica, mas, por mediações, na formação dos professores de educação física.

As proposições reivindicadas pela autora fracassaram ao longo do processo de construção da reforma educacional, o que não quer dizer que não tenham orientado a resistência de muitos educadores, muito menos que deixaram, pela derrota pontual, de continuar plenamente atuais.

\section{Considerações finais}

A orientação que se impôs à educação nacional - da mesma forma que se impôs em escala mundial - expressa o paroxismo das contradições do atual modo de produção. Aponta, portanto, para um esgotamento da produção fundada na relação capital versus trabalho.

A superação dessa relação matricial cabe exclusivamente aos trabalhadores e se inscreve nos marcos da luta de classes. Para além dos limites impostos pelo modo de produção capitalista, sempre persistem as fissuras das contradições, nas quais se abrem possibilidades de esperança de que se possa imprimir à subjetividade dos educadores a compreensão, frequentemente obscurecida, de que eles, queiram ou não, integram a classe trabalhadora, a única que tem interesse amplo e legítimo no revolucionamento do ser social.

\section{Referências}

ABRAMIDES, M. B. C.; CABRAL, M. S. R. Regime de acumulação flexível e saúde do trabalhador. São Paulo em Perspectiva, São Paulo, v. 17, n. 1, p. 3-10, jan./mar. 2003. DOI: 10.1590/S0102-88392003000100002

BANCO MUNDIAL. Prioridade y estratégias para la educación. Washington, DC: World Bank, 1996.

BRASIL. CONSELHO FEDERAL DE EDUCAÇÃO. Resolução n. 03, de 16 de junho de 1987. Fixa os mínimos de conteúdo e duração a serem observados nos cursos de graduação em Educação Física (Bacharelado e/ou Licenciatura Plena). Diário Oficial da União, Brasília, DF, 10 set. 1987. 
BRASIL. Lei n. 9.394, de 20 de dezembro de 1996. Lei de Diretrizes e Bases da Educação Nacional. Diário Oficial da União, Brasília, DF, 23 dez. 1996.

BRASIL. Portaria n. 146, de 10 de março de 1998. Brasília: Secretaria de Ensino Superior, Ministério da Educação, 1998.

BRASIL. Parecer CNE/CP n. 009, de 08 de abril de 2001. Diretrizes Curriculares Nacionais para a Formação de Professores da Educação Básica, em nível superior, curso de licenciatura, de graduação plena. Conselho Nacional de Educação, Brasília, 2001.

BRASIL. Conselho Nacional de Educação. Parecer n. 0138, de 03 de abril de 2002. Diretrizes Curriculares Nacionais do Curso de Graduação em Educação Física. Câmara de Ensino Superior do Conselho Nacional de Educação, Brasília, 2002.

BRASIL. Conselho Nacional de Educação. Resolução n. 07, de 31 de março de 2004. Institui as Diretrizes Curriculares Nacionais para os cursos de graduação em Educação Física, em nível superior de graduação plena. Câmara de Ensino Superior do Conselho Nacional de Educação, Brasília, 2004.

BRASIL. Ministério da Educação. Secretaria da Educação Fundamental. "Declaração Mundial sobre Educação para Todos: satisfação das necessidades básicas de aprendizagem". In: BRASIL. Ministério da Educação. Plano decenal de educação para todos. Brasília, MEC/SEF, 1993.

BRASIL. Referenciais para formação de professores. Brasilia: MEC/SEF, 1998.

CEPAL. Transformación productiva com equidad. Santiago de Chile: Naciones Unidas (Comision Economica para America Latina y el Caribe), 1990.

DUARTE, N. A individualidade para si: contribuições a uma teoria histórico-crítica da formação do indivíduo. 3. ed. Campinas: Autores Associados, 2013.

GRADELLA J. R. O sofrimento psíquico e trabalho intelectual. Cadernos de Psicologia Social do Trabalho, São Paulo, v. 13, n. 01, p. 133-148, 2010. DOI: 10.11606/issn.19810490.v13i1p133-148

HARVEY, D. Condição pós-moderna: uma pesquisa sobre as origens da mudança cultural. 22. ed. São Paulo: Loyola, 2012.

KUENZER, A. Z. Da dualidade assumida à dualidade negada: o discurso da flexibilização justificada a inclusão excludente. Educação \& Sociedade, Campinas, v. 28, n. 100 (Especial), p. 1153-1178, out. 2007. DOI: 10.1590/S0101-73302007000300024

MARTINS, L. M. A formação social da personalidade do professor: um enfoque vigotskiano. Campinas: Autores Associados, 2011.

MARX, K.; ENGELS, F. A Ideologia Alemã (I - Feuerbach). Tradução de Jose Carlos Bruni e Marco Aurélio Nogueira. 10. ed. São Paulo: Hucitec, 1996.

MAZZEU, L. T. B. A política educacional e a formação de professores: reflexões sobre os fundamentos teóricos e epistemológicos da reforma. In: MARSIGLIA, A. C. G. (Org.). Pedagogia histórico-crítica: 30 anos. Campinas: Autores Associados, 2011. p. 147-167.

MORAES, M. C. M. Proposições acerca da produção de conhecimento e políticas de formação docente. In: MORAES, M. C. M. (Org.). Iluminismo às avessas: produção de conhecimento e políticas de formação docente. Rio de Janeiro: DP\&A, 2003. p. 07-20. 
NETTTO, J. P. Crise do socialismo e ofensiva neoliberal. São Paulo: Cortez, 1994.

NET'TO, J. P.; BRAZ, M. Economia crítica: uma introdução crítica. 7. ed. São Paulo: Cortez, 2011.

TAFFAREL, C. N. Z. Do trabalho em geral ao trabalho pedagógico: contribuição ao debate sobre o trabalho pedagógico na Educação Física. Motrivivência, ano XXII, n. 35, p. 18-40, dez. 2010. DOI: 10.5007/2175-8042.2010v22n35p18

TAFFAREL, C. N. Z.; LACKS, S. Diretrizes curriculares: proposições superadoras para a formação humana. In: FIGUEIREDO, Z. C. C. (Org.). Formação profissional em educação física e mundo do trabalho. Vitória: Gráfica da Faculdade Salesiano, 2005. p. 89-110.

TAFFAREL, C. N. Z.; SANTOS JR., C. L. Nexos e determinações entre formação de professores de Educação Física e diretrizes curriculares: competências para quê?. In: FIGUEIREDO, Z. C. C. (Org.). Formação profissional em educação física e mundo do trabalho. Vitória: Gráfica da Faculdade Salesiano, 2005. p. 111-136.

TEIXEIRA, L. Pedagogia histórico-crítica: contribuições para a superação do conhecimento tácito na formação de professores. In: MARSIGLIA, A. C. G. (Org.). Infância e pedagogia histórico-crítica. Campinas: Autores Associados, 2013. p. 17-34.

SAVIANI, D. Perspectiva marxiana do problema subjetividade-intersubjetividade. In: DUARTE, N. (Org.). Crítica ao fetichismo da individualidade. Campinas: Autores Associados, 2004. p. 21-52.

SAVIANI, D. História das ideias pedagógicas no Brasil. 3. ed. 1. Reimpr. Campinas: Autores Associados, 2011.

Recebido em 25/11/2013

Versão final recebida em 30/05/2014

Aceito em 07/06/2014 